\title{
THERMAL BARRIER COATING LIFE PREDICTION MODEL DEVELOPMENT1
}

\author{
J.T. DeMasi, S.L. Manning, M. Ortiz, and K.D. Sheffler \\ Pratt \& Whitney Division \\ United Technologies Corporation \\ East Hartford, Connecticut
}

The objectives of this program are to increase understanding of Thermal Barrier Coating (TBC) degredation and failure modes, to generate quantitative ceramic failure life data under cyclic thermal conditions which simulate those encountered in gas turbine engine service, and to develop an analytical methodology for prediction of coating life in the engine.

This program is being conducted in two phases. The first phase, which is complete, was conducted with a plasma deposited thermal barrier coating system, designated PWA 264, which currently is bill-of-material on various stationary turbine components in several commercial engines. The second phase, which was initiated in July 1987, will adapt the plasma deposited life model to a more recently developed electron beam-physical vapor deposited ceramic coating, designated PWA 266, which has shown the potential to provide up to ten times the cyclic thermal coating durability of the plasma deposited coating. These two coatings are compared in Figure 1 .

\section{Phase I - Plasma Deposited Ceramic}

Phase I observations of degredation and failure modes in plasma deposited ceramic indicate that spallation failure results from progressive cracking of the ceramic parallel to and adjacent to, but not coincident with the metal-ceramic interface. Typical ceramic failures are shown in Figure 2. Figure 3 shows the progressive accumulation of ceramic cracking damage in laboratory specimens suspended from test at various fractions of their spallation life.

Phenomenological evidence obtained by burner rig testing of specimens pre-exposed in oxidizing and non-oxidizing environments indicates that oxidation is involved in the degredation process. Test results plotted in Figure 4 clearly show a substantial reduction of life for air pre-exposed specimens, with no such reduction seen for specimens pre-exposed in Argon.

Based on the observation of mechanical failure within the ceramic layer, effort was devoted to exploration of ceramic mechanical behavior. A significant conclusion from this work was the observation of substantial inelastic deformation at all temperatures from ambient to $1204^{\circ} \mathrm{C}\left(2200^{\circ} \mathrm{F}\right)$.

1 NASA Contract NAS3-23944 
Uniaxial tensile stress-strain curves obtained on the plasma deposited ceramic at room temperature and $1204^{\circ} \mathrm{C}\left(2200^{\circ} \mathrm{F}\right.$ ) (Figure 5) clearly show this non-linear deformation. A typical uniaxial compression stress-strain curve (Figure 6) exhibits a combination of linear and non-linear behavior with substantially higher strength than in tension. A hysteres is loop obtained by reversing the orientation of a strain gauged room temperature four point bend specimen at zero load (Figure 7) exhibits significant reversed inelastic strain. ("Kinks" in this curve at the zero load crossing are thought to result from slight material recovery during the time required to reverse the orientation of the specimen.) Evidence of significant creep at $982^{\circ} \mathrm{C}\left(1800^{\circ} \mathrm{F}\right)$ and of exceptionally stress sensitive fatigue failure $(b \approx 50)$ are shown in Figure 8 .

Following the approach of Miller (1), an existing fatigue model was selected as the basis for the TBC life prediction model (Figure 9). The mechanical damage driver in this model is inelastic strain range $\left(\Delta \varepsilon_{\mathbf{i}}\right)$. Environmental degradation is accounted for by incorporating the proportionality constant in the exponential term and causing it to be dependerit on progressive oxidation damage (Figure 10).

To calculate inelastic strain range for incorporation in the life model, ceramic constituitive behavior was fitted to a time dependent inelastic model developed by Walker (2). An example of the application of this model is shown in Figure 11, where calculated tensile and compressive strains are compared with measured data. A. Walker model calculation of ceramic stress-strain behavior for a typical TBC thermal cycle (Figure 12), clearly shows the large amount of reversed inelastic strain produced by thermal cycling of the TBC system.

Prediction of oxide thickness as a function of time and temperature for incorporation in the life model was based on an oxidation model developed at NASA (3). Constants for this model were established by correlation of oxide thickness measured on laboratory exposed specimens of the thermal barrier coating system (Figure 13).

Experimental TBC spallation life data for calibration of the life model constants was obtained from cyclic burner rig tests of a rotating, externally heated and internally cooled hollow cylindrical specimen illustrated in Figure 14. Burner rig test conditions (maximum and minimum cycle temperature and time at maximum temperature) were varied in each test to vary the relative emphasis on each of the two primary life drivers (inelastic strain range and oxide thickness) as illustrated in Figure 15. Results of twenty such tests were correlated with the life model to produce best fit values of the model constants shown in Figure 16. Results of this correlation show calculated life to be within a factor of \pm 3 of observed life for nineteen of the twenty experimental results (Figure 17). The twentieth data point could not be correctly predicted with any reasonable variation of the model constants, and is assumed to be in error. 
To substantiate the life prediction model, six additional tests were conducted, four using the previously described burner rig test method and two using a radiant source to heat a flat panel coated with plasma TBC. The primary differences in the two test methods are the specimen geometry and the substantially higher heat flux obtained from the radiant source, which more closely simulates that experienced in the gas turbine engine. Results of these tests are included in Figure 17, and are seen to be within the $\pm 3 X$ deviation band, thus substantiating the prediction capability of the model.

To summarize results of the first phase of this program, plasma deposited TBC ceramic spallation has been observed to result from progressive near interfacial cracking of the ceramic. Phenomenological evidence indicates that interfacial oxidation accelerates this process. Mechanical behavior of the ceramic has been found to be unusual, exhibiting highly inelastic stress strain behavior at ambient temperature, creep, fatigue, and cyclically reversible inelastic deformation. A life prediction model has been developed which incorporates cyclic inelastic strain and interfacial oxidation as the primary degredation modes. This model has been shown to correlate cyclic thermal spallation life results within a factor of \pm 3 over a broad range of relative mechanical and oxidative exposure severities.

\section{PHASE. II - Electron Beam-Physical Vapor Deposited Ceramic}

The goals of the second phase of this program are similar to those of the first phase; that is, to understand the degredation and failure modes of the Electron Beam-Physical Vapor Deposited ceramic shown on the right in Figure 1, to generate quantitative failure data, and to develop a life prediction model for this ceramic.

Preliminary results show the EB-PVD ceramic to be at least four to ten times as spallation resistant as the plasma deposited ceramic, depending on the relative severities of the oxidative vs. mechanical damage induced by exposure (Figure 18). (In some of these tests, failure of the specimen was initiated by thermal fatigue cracking of the B-1900 + Hf substrate, suggesting that the life increase of the EB-PVD ceramic may be greater than that shown in Figure 18). This relative durability improvement has been substantiated in side-by-side field service testing of plasma and EB-PVD ceramic, as shown in Figure 19. Examination of spalled EB-PVD ceramic shows the failure mode to be different from plasma TBC. Whereas the plasma system fails as a result of cracking in the ceramic layer, EB-PVD ceramic failure occurs predominantly at the metal-ceramic interface, as shown in Figure 20.

The approach which will be taken to model the spallation life of the EB-PVD ceramic coating is outlined in Figure 21 . The program objectives 
will be accomplished in four tasks, numbered $V$ through VIII. Task $V$ will involve evaluation and modeling of EB-PVD ceramic mechanic behavior, while in Task VI, oxidation at the metal-ceramic interface will be measured and modeled. Quantitative life data will be generated and modeled over a broad range of relative oxidizing and mechanical severities in Phase VII, and in Phase VIII substantiation tests will be conducted to verify the model. It is anticipated that this effort will take fifteen months starting from July 1987.

\section{REFERENCES}

1. Miller, R.A., "Oxidation-Based Model for Thermal Barrier Coating Life", J. Am. Cer. Soc., V.67, No: 8, pp 517-521, 1984.

2. Walker, K.P., "Research and Development Program for Non-Linear Structural Modeling with Advanced Time-Temperature Dependent Constituitive Relationships", NASA CR 165533.

3. Miller, R.A., Private Communication 


\section{ORIGINAL PAGE IS \\ OF POOR QUALITY}

Phase I

Plasma deposited ceramic

(PWA 264)

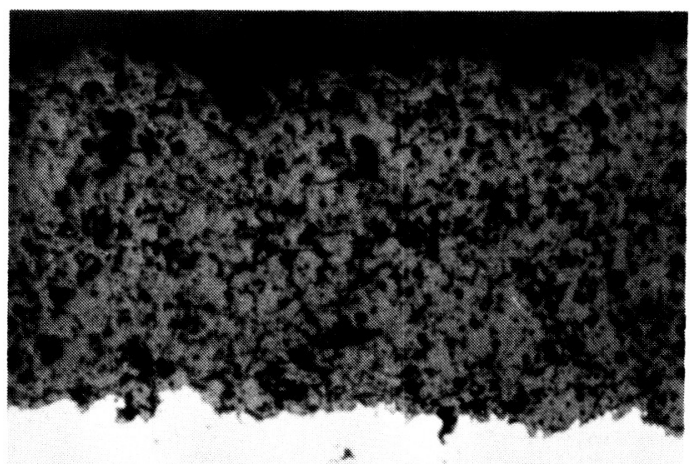

Bill-of-material

JT9D

PW2037

PW4000

V2500
Phase II

Electron beam - physical vapor deposited ceramic (PWA 266)

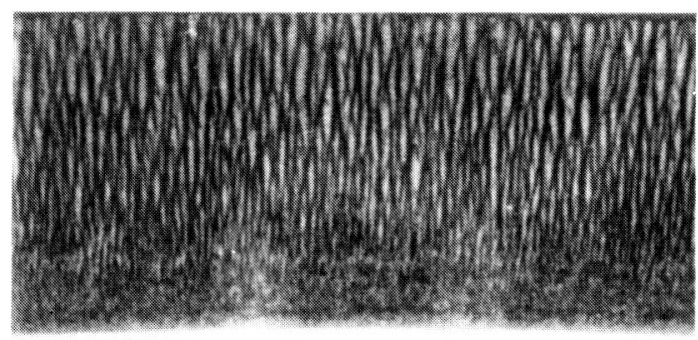

Figure 1 Program Conducted in Two Phases

Engine

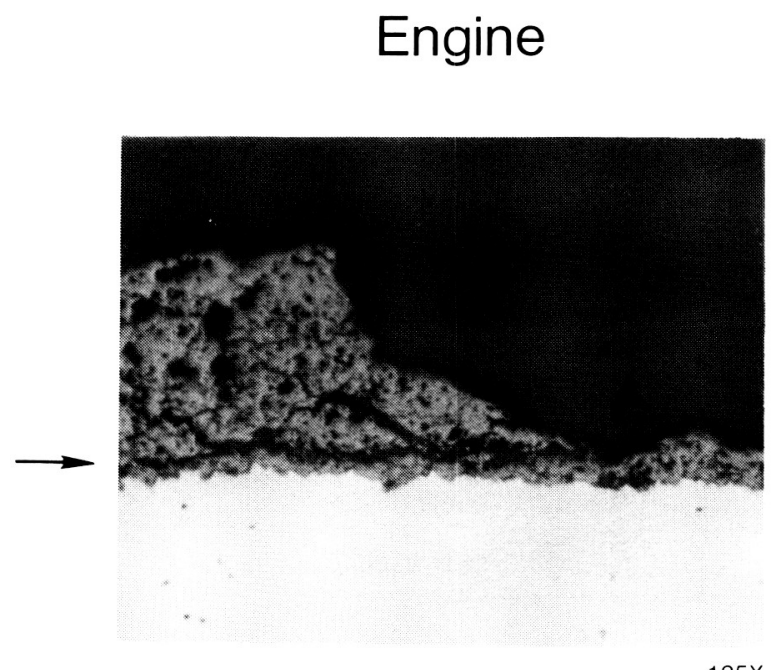

$125 x$
Advanced coating

offers substantially improved coating durability

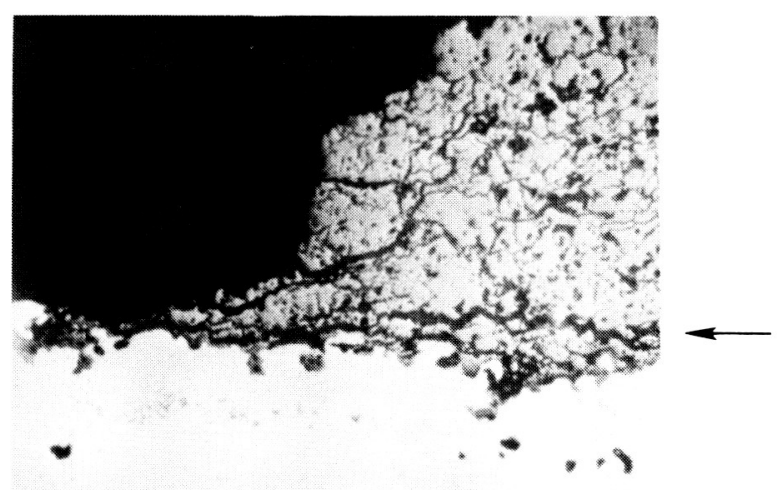

Lab test

\section{Arrows indicate primary failure sites}

Figure 2 Typical Ceramic Failures 

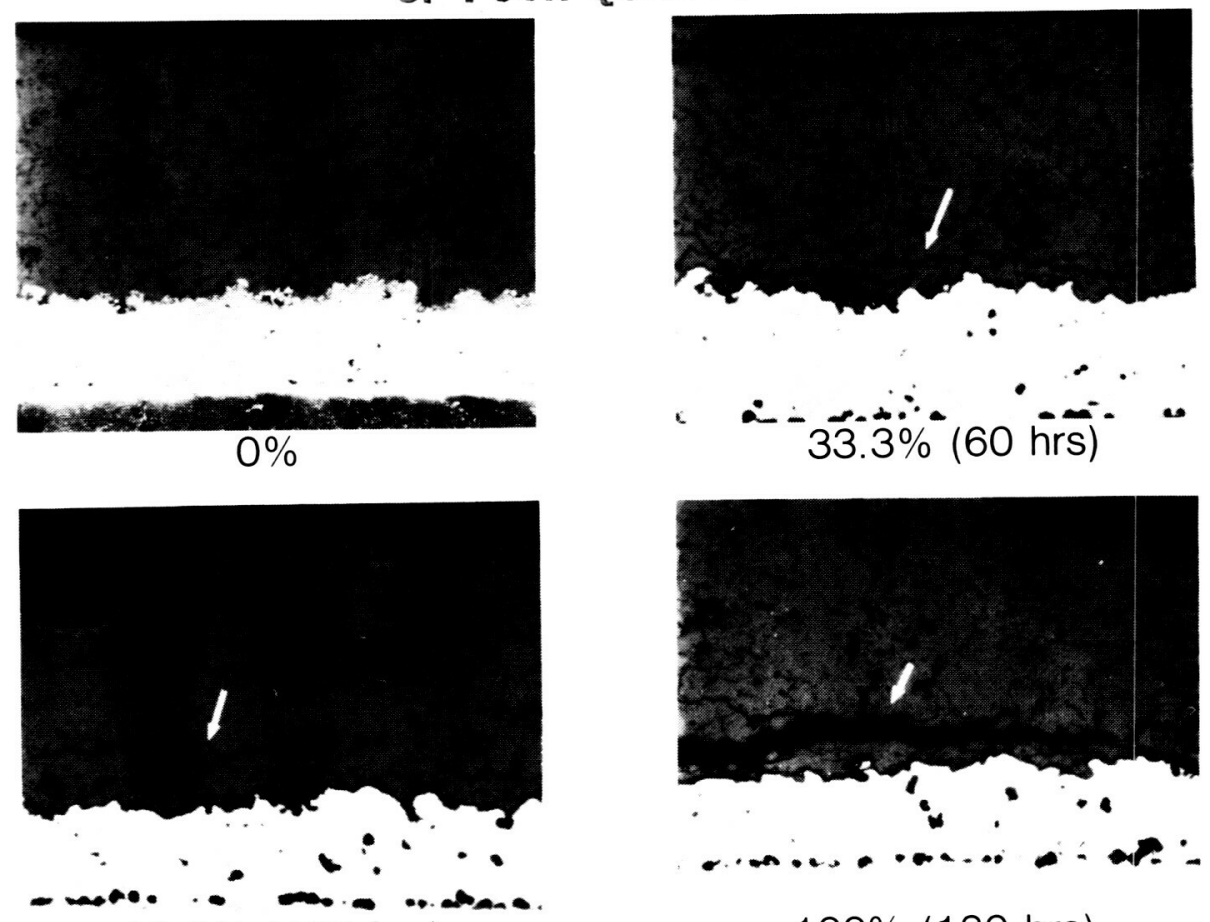

$66.6 \%$ (120 hrs)

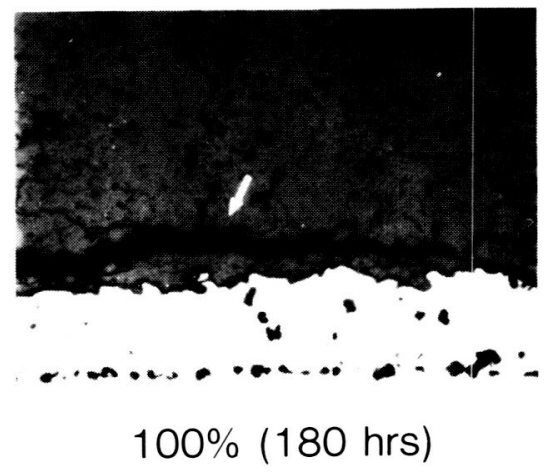

Figure 3 Ceramic Cracking Damage Accumulates Progressively

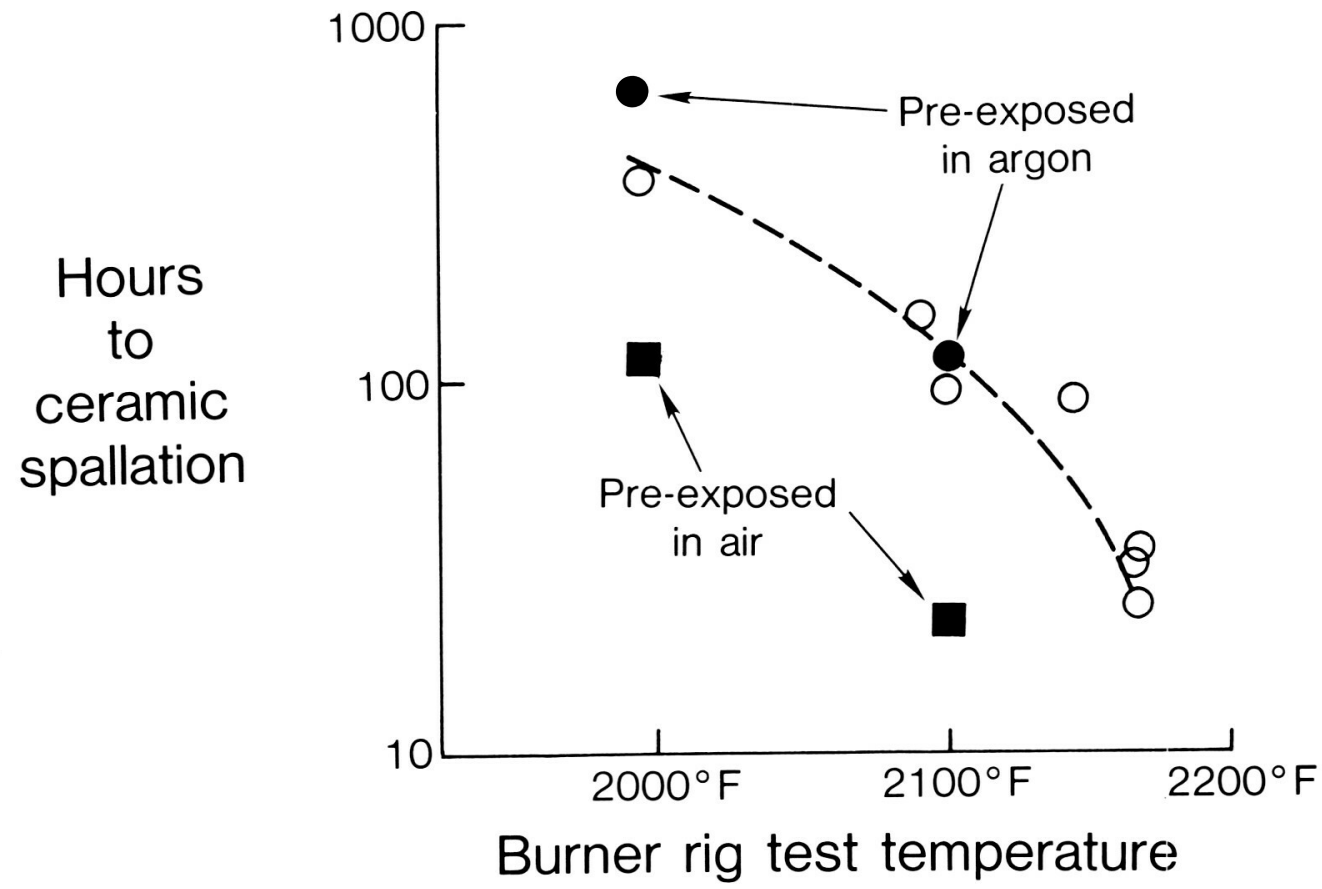

Figure 4 Phenomenological Evidence Suggests Environmental Interaction 


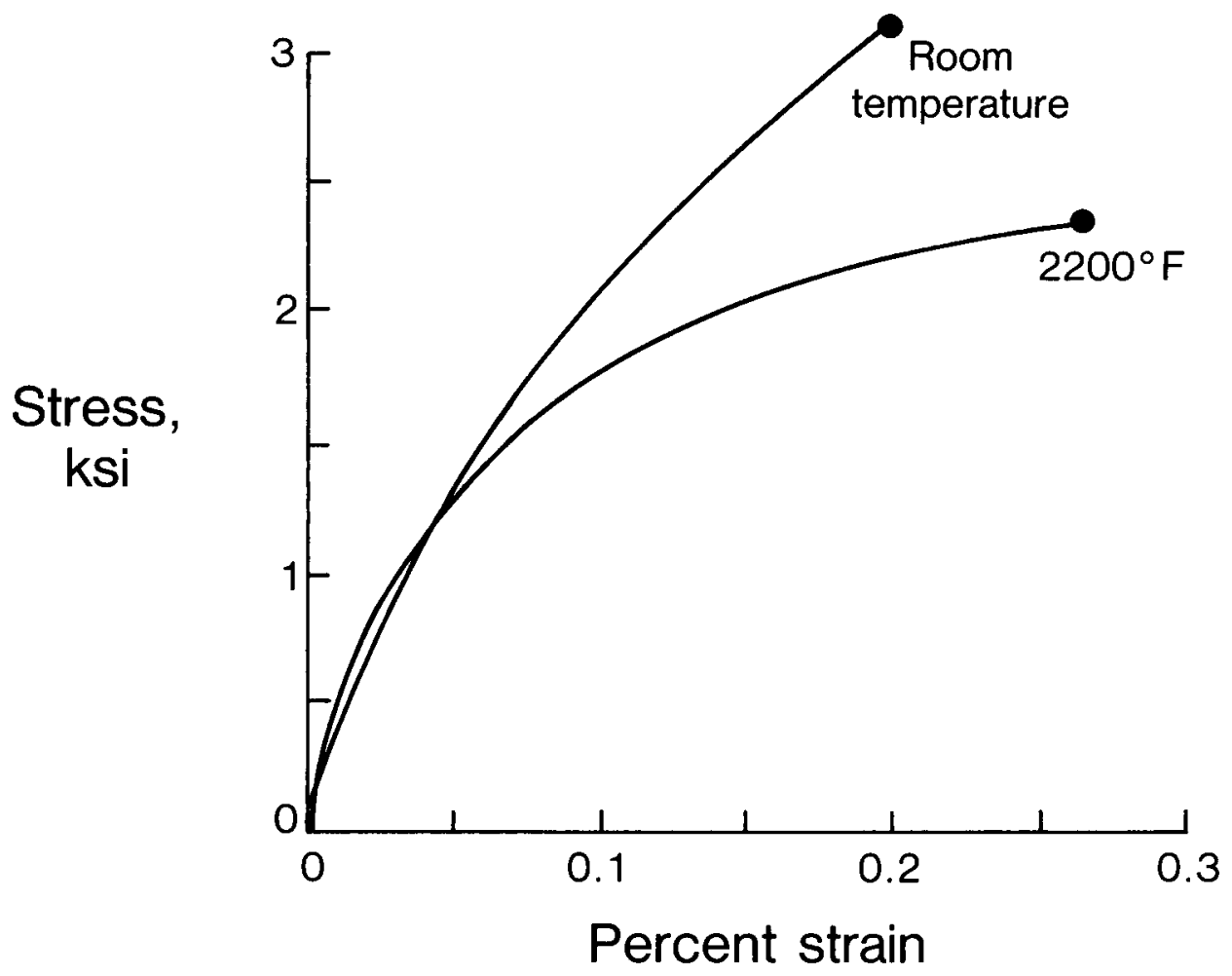

Figure 5 Ceramic Tensile Deformation Completely Inelastic

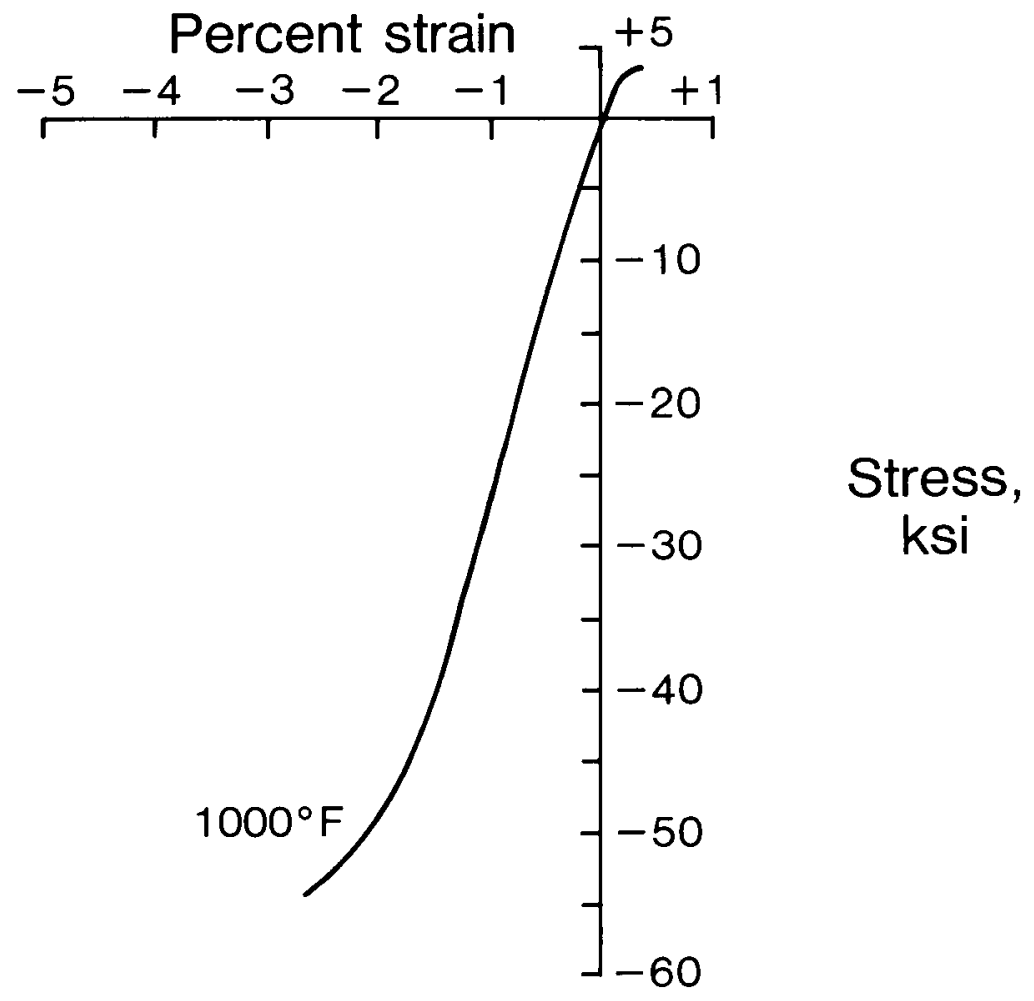

Figure 6 Ceramic Compressive Deformation is Elastic/Inelastic 


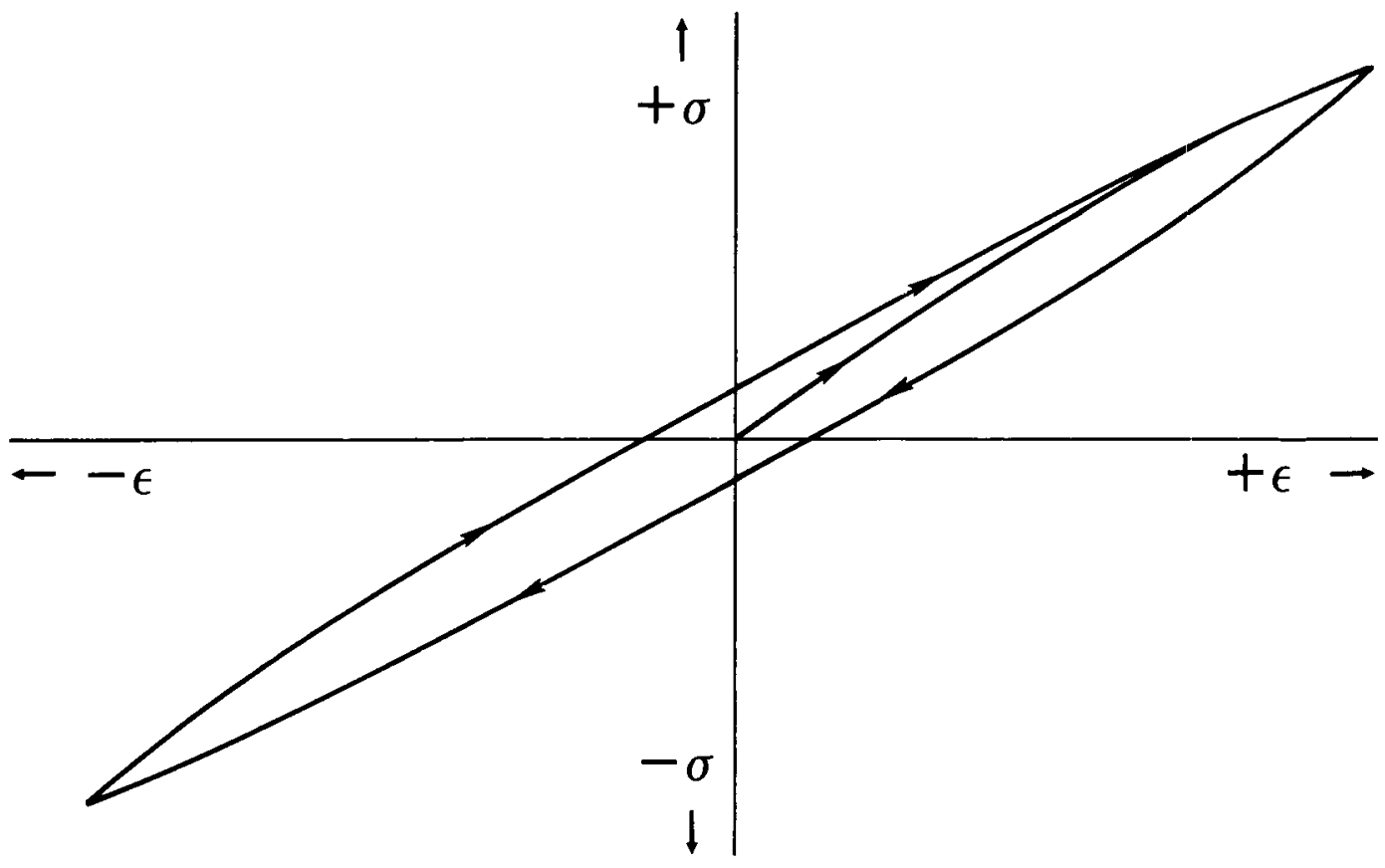

Figure 7 Reversed Deformation Exhibits Significant Hysteres is

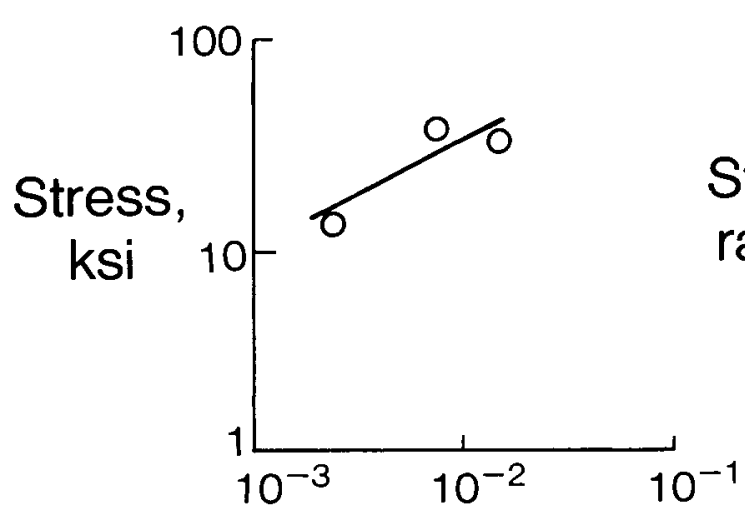

Creep rate, $\mathrm{Hr}^{-1}$

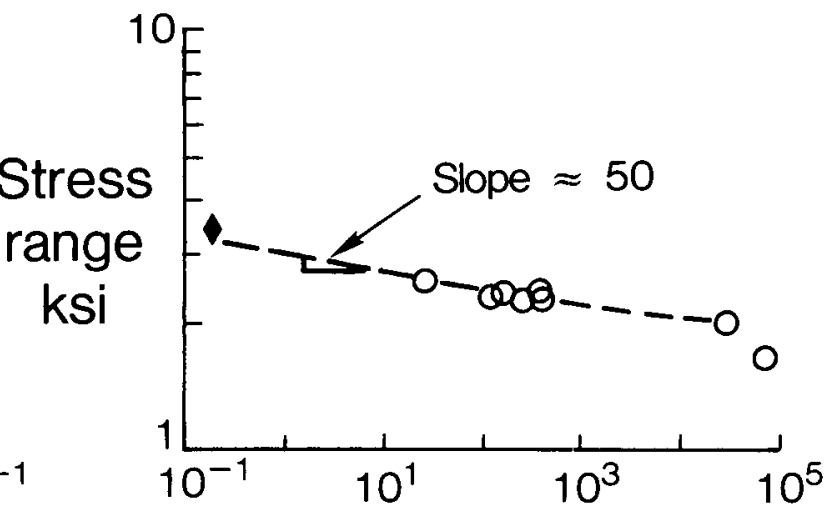

Fatigue cycles to failure

Figure 8 Ceramic Exhibits Significant Creep and Fatigue 


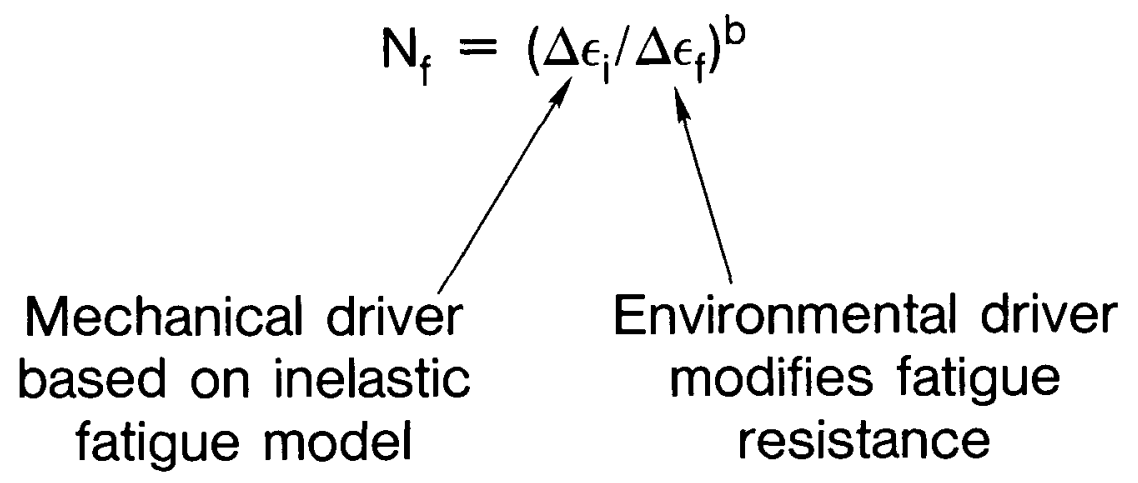

Figure 9 Life Prediction Model Incorporates Mechanical and Environmental Drivers

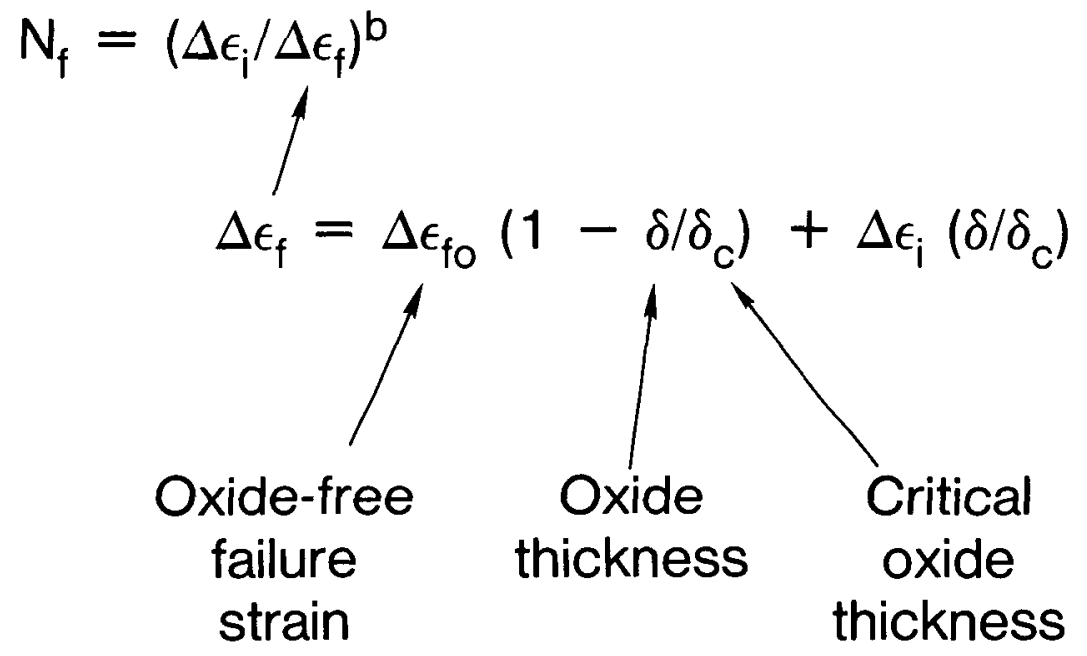

Figure 10 Environmental Driver Modifies Fatigue Resistance 


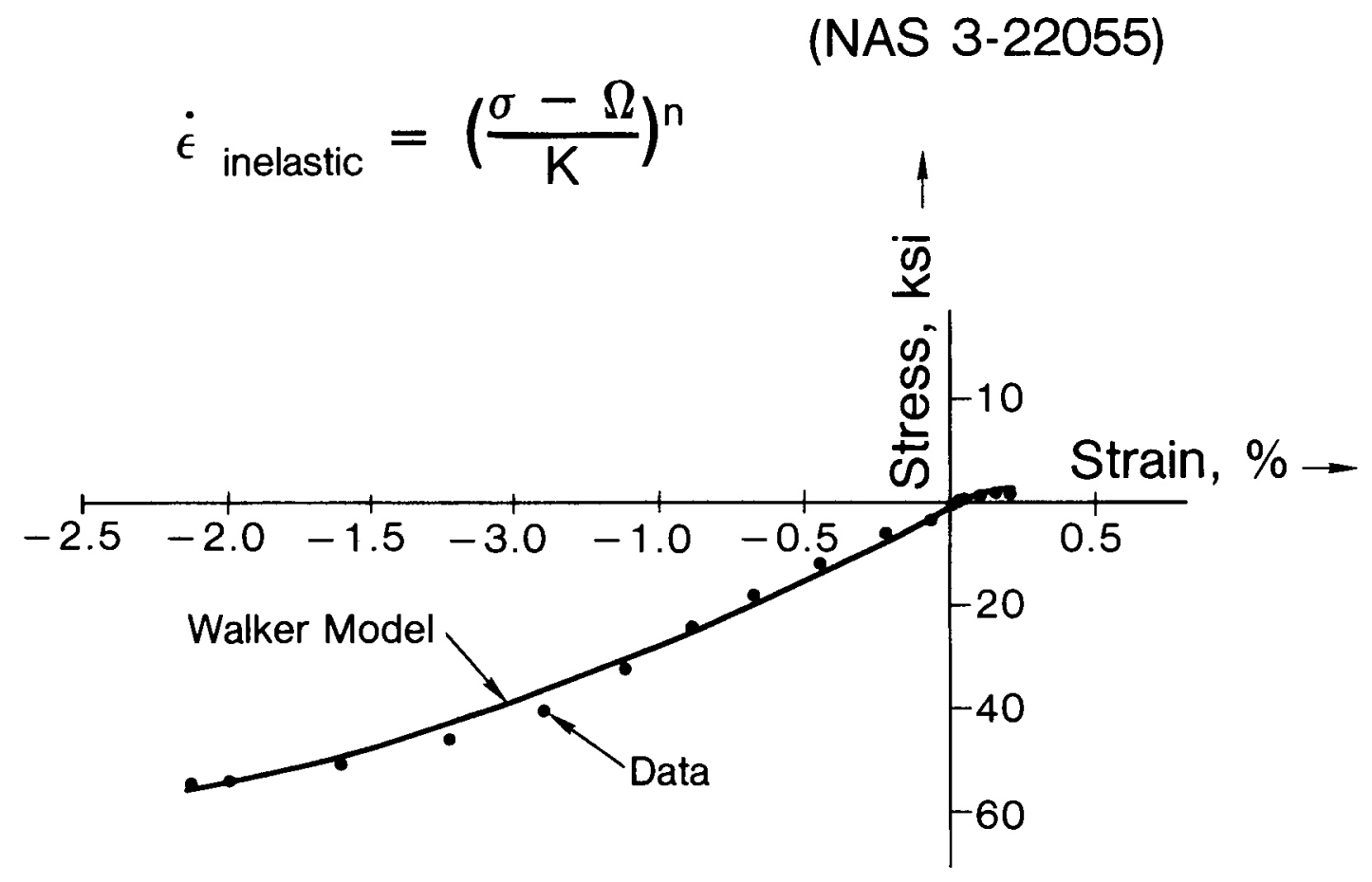

Figure 11 Ceramic Behavior Modeled With Walker Equation

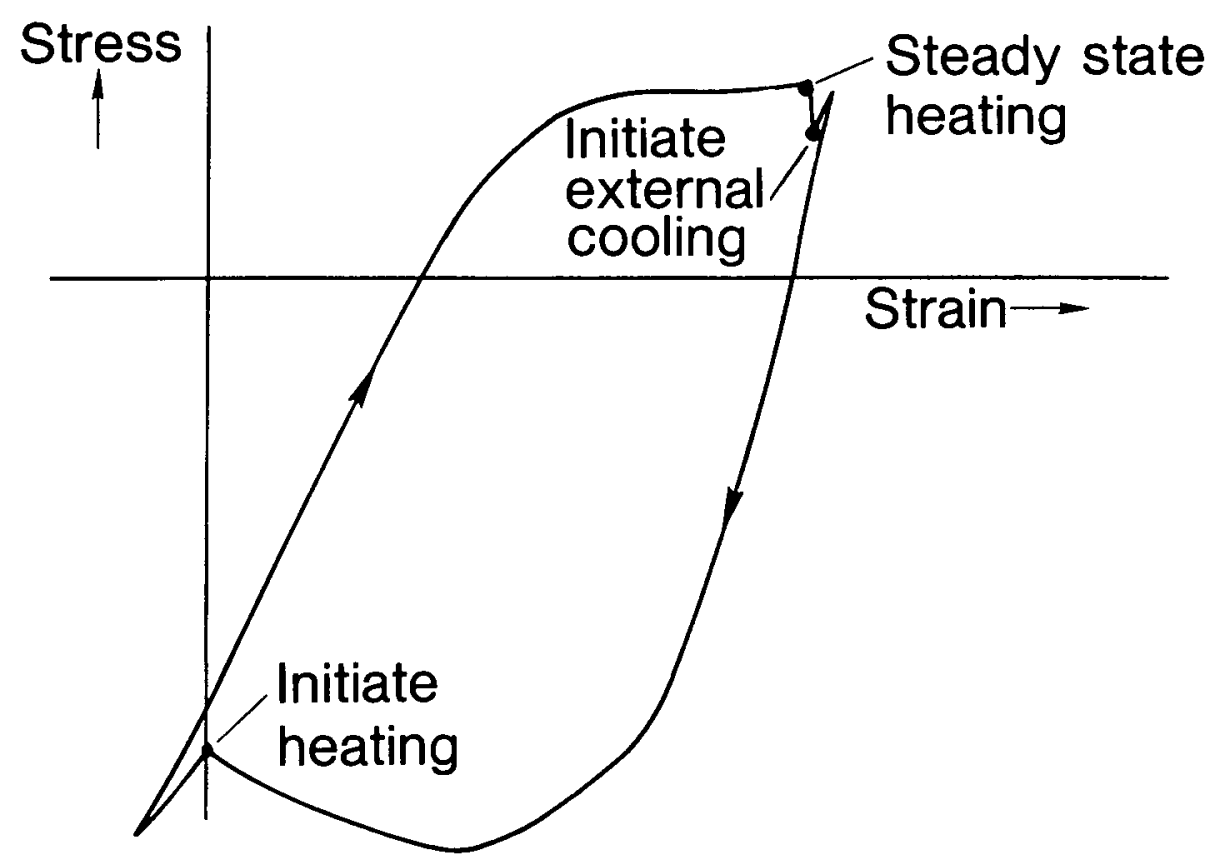

Figure 12 Walker Model Predicts Large Reversed Inelastic Strain Range 
$\triangle$ Oxide emphasis

Strain emphasis

$\Delta$ Mixed made

$$
\begin{aligned}
\delta & =1.20 \times 10^{-4}\left(5.714 \times 10^{11} \mathrm{e} .104856 / \mathrm{RT}_{\mathrm{t}}\right) 0.5 \\
\mathrm{R} & =1.987, \delta=(\mathrm{CM}) \\
\mathrm{T} & =\left({ }^{\circ} \mathrm{K}\right) \\
\mathrm{t} & =(\mathrm{SEC})
\end{aligned}
$$

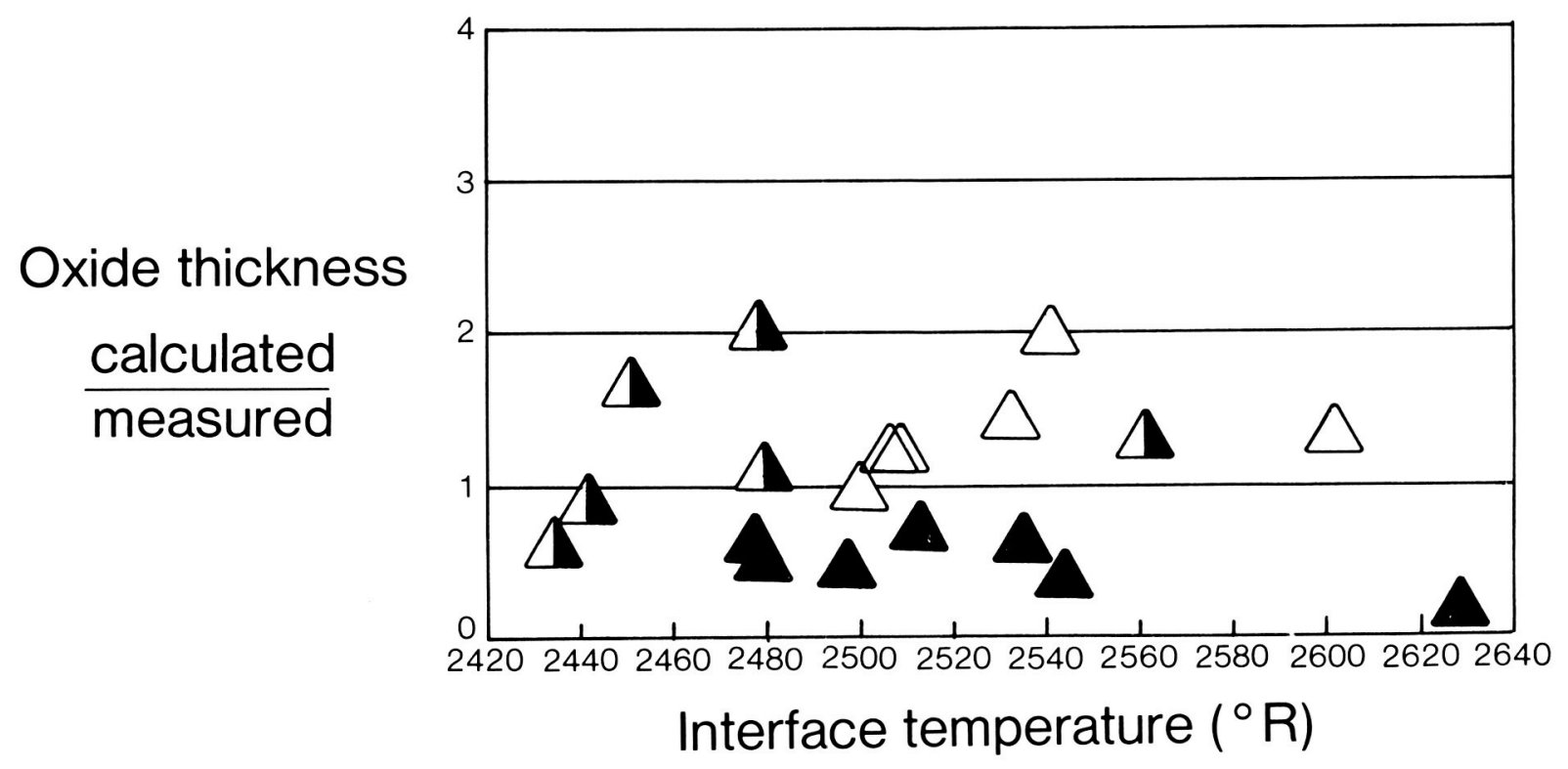

Figure 13 Oxidation Driver Based on Modified INASA Model
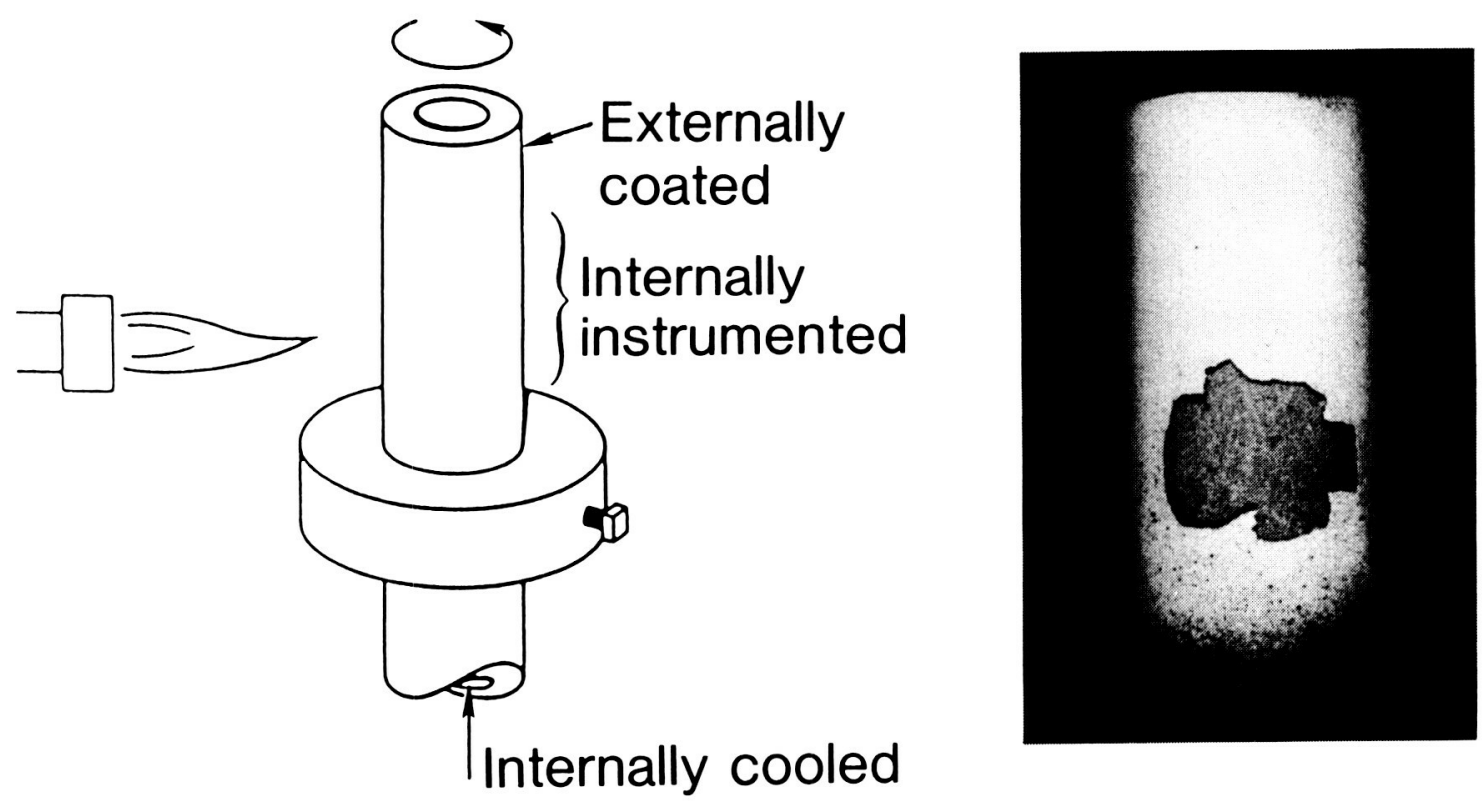

Figure 14 Design Data Generated With Internally Cooled Specimen 


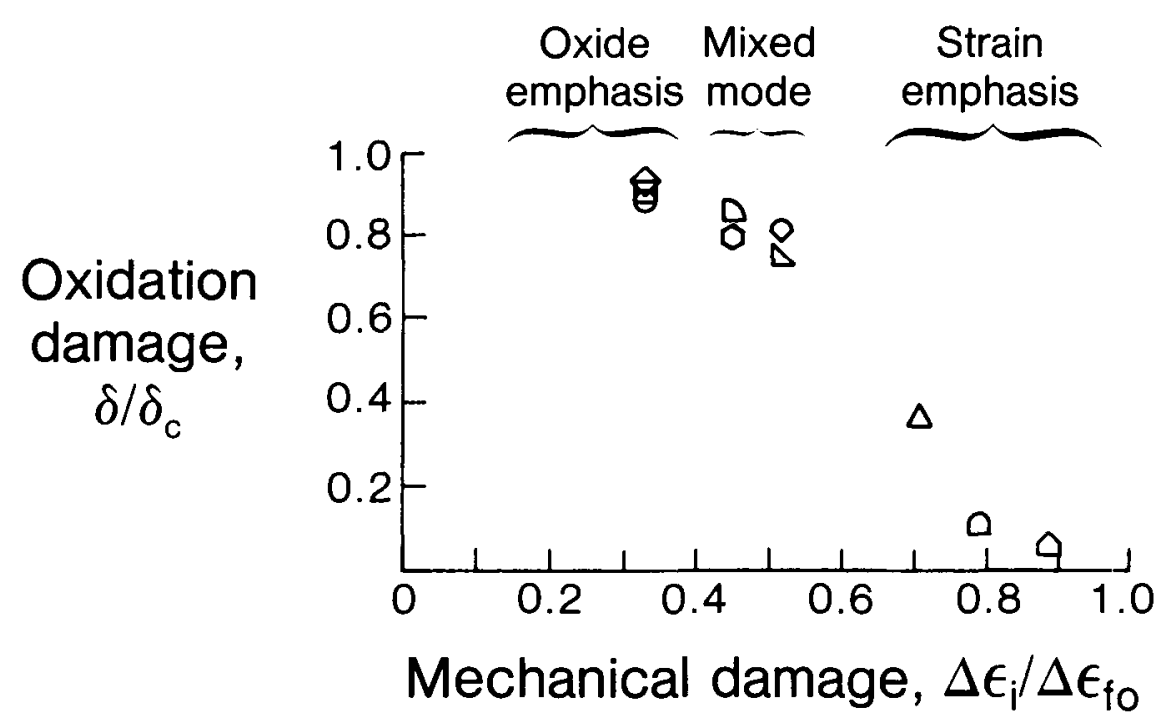

Figure 15 Design Data Tests Cover Wide Range of Mechanical and Oxide Induced Damage

$$
\begin{aligned}
N_{\mathrm{f}}= & \left(\Delta \epsilon_{\mathrm{i}} /\left[\Delta \epsilon_{\mathrm{fo}}\left(1-\delta / \delta_{\mathrm{c}}\right)+\Delta \epsilon_{\mathrm{i}}\left(\delta / \delta_{\mathrm{c}}\right)\right]\right)^{\mathrm{b}} \\
\Delta \epsilon_{\mathrm{fo}} & =0.0040 ; \text { static failure strain } \\
\delta_{\mathrm{c}} & =0.000370 \text { in.; critical oxide thickness } \\
\mathrm{b} & =-10.87
\end{aligned}
$$

Figure 16 Correlation of Design Data Provides "Best Fit" Constants 
Design data tests

- Substantiation tests - burner rig

a Substantiation tests - quartz lamp heater

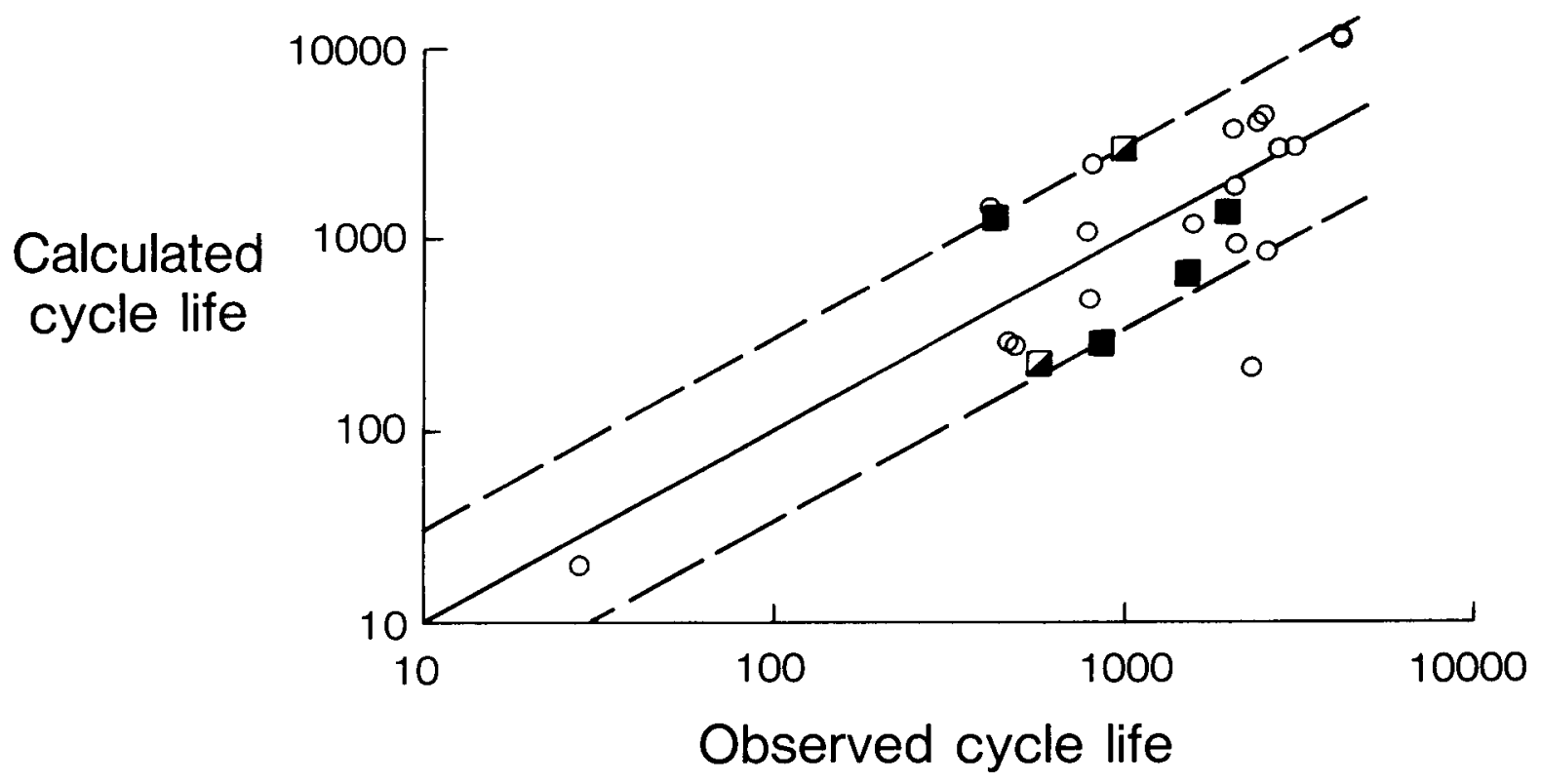

Figure 17 optimized Correlation $+3 x$ on Life

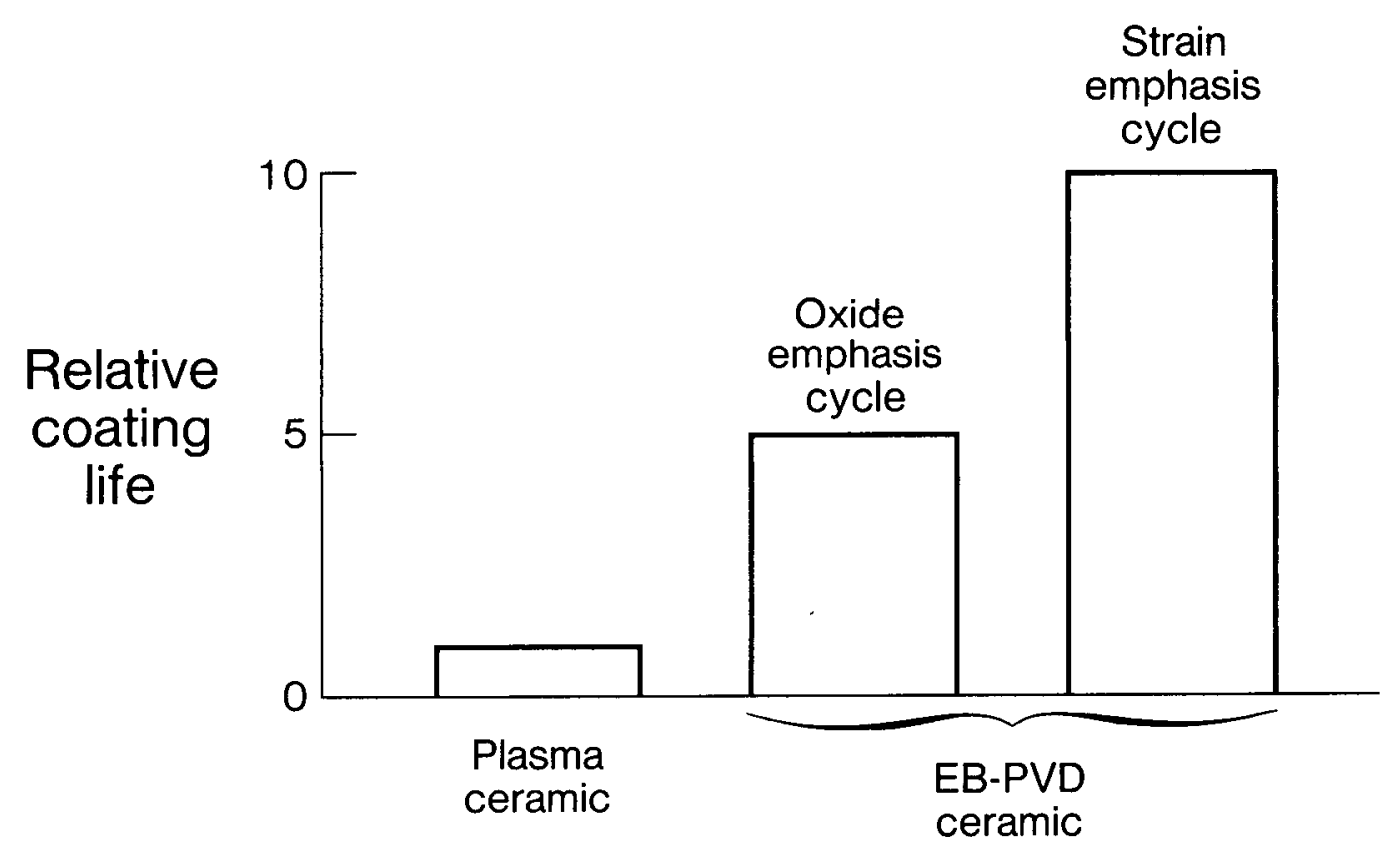

Figure 18 EB-PVD Ceramic Benefits Are Cycle Dependent 
ORIONAE PACE IS

OF POOR QUALITY

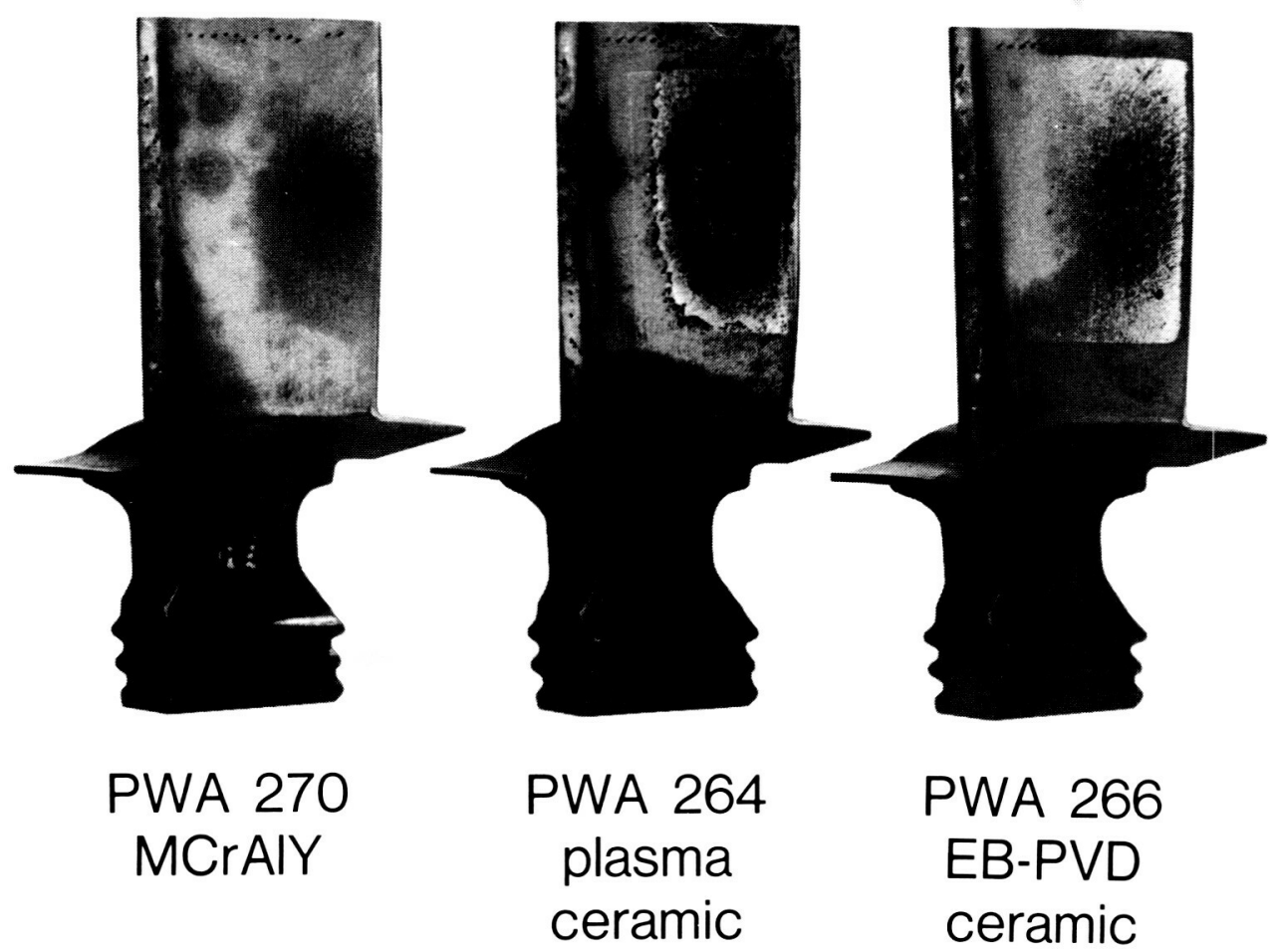

Figure 19 EB-PVD Ceramic Engine Evaluation

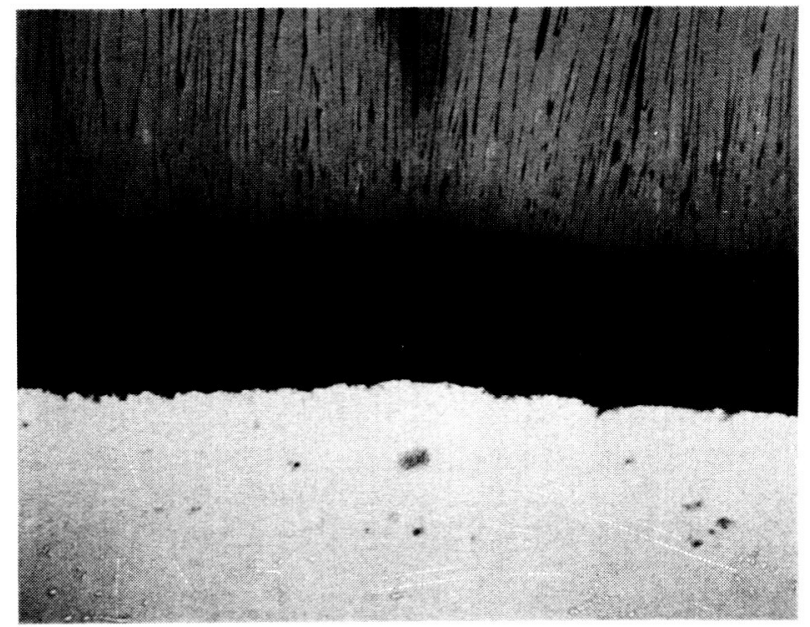

Figure 20 EB-PVD Ceramic Fails at Interface 


\section{Task V Evaluate mechanical driver \\ - Property evaluation \\ - Modeling}

Task VI Evaluate environmental driver

- Measure oxidation kinetics

- Modeling

Task VII Life correlation

- Generate life data

- Correlate model

Task VIII Verification testing

Figure 21 Phase II Program Approach 